Gut, 1979, 20, 705-708

\title{
Reappraisal of the secretory potency and disappearance rate of pure human minigastrin
}

\author{
D. C. CARTER, I. L. TAYLOR, JANET ELASHOFF, AND \\ M. I. GROSSMAN ${ }^{1}$
}

From the VA Wadsworth Hospital Center and UCLA School of Medicine, Los Angeles, California, USA

SUMMARY The secretory potency and disappearance rates of pure synthetic human non-sulphated minigastrin (HG-14-I) and pure natural human non-sulphated heptadecapeptide (HG-17-I) were compared in five dogs with gastric fistulas and Heidenhain pouches. Intravenous infusion of equimolar doses of the two gastrins produced equimolar increases over basal of serum immunoreactive gastrin and no statistically significant differences in acid output. Also HG-14-I and HG-17-I did not differ significantly in half-times for disappearance, clearance rates, calculated volumes of distribution, or mean plateau serum levels.

Minigastrin is the trivial name for a biologically active form of gastrin first isolated from gastrinoma tissue by Gregory and Tracy (1974) and thought initially to contain one tryptophan residue in a total of 13 amino-acid residues. It has since become apparent (Gregory et al., 1979) that minigastrin contains an additional tryptophan at the $\mathrm{N}$-terminus, bringing the total of amino-acid residues to 14 . Human minigastrin is now designated correctly as HG-14-I or HG-14-II according to the absence (I) or presence (II) of sulphation of the single tyrosine residue.

A previous study from this laboratory compared the secretory potency of pure natural HG-14-I and HG-17-I in dogs with gastric fistulae and Heidenhain pouches (Debas et al., 1974). Minigastrin appeared to be less than half as potent as HG-17-I in stimulating acid secretion, but it is now apparent that failure to appreciate the second tryptophan residue caused an error in calculating the extinction coefficient and consequently in determining the molar concentration of the minigastrin solution. As a result, equimolar infusion rates of minigastrin and HG-17-I were not achieved.

The present study compares the secretory potency and disappearance rates of pure synthetic HG-14-I and pure natural HG-17-I in dogs.

\footnotetext{
${ }^{1}$ Address for correspondence: Dr M. I. Grossman, VA Wadsworth Hospital Center, Building 115, Room 115, Los Angeles, California 90073, USA.
}

Received for publication 21 March 1979

\section{Methods}

GASTRIN

HG-14-I was synthesised by S. Moore and G. W. Kenner, and purified by R. A. Gregory (University of Liverpool). Pure HG-17-I was prepared from human gastrinoma tissue by R. A. Gregory and $\mathrm{H}$. Tracy. The gastrins were dissolved in $0 \cdot 1 \mathrm{M} \mathrm{NH}_{4} \mathrm{OH}$ and their molar concentrations were determined by measuring absorbance at $\mathbf{2 8 0} \mathrm{nm}$ in a Zeiss PMQ-I spectrophotometer (Carl Zeiss Inc., New York) and dividing the absorbance by the extinction coefficient (12,261 for both gastrins).

\section{ANIMALS}

Five mongrel dogs weighing between 18 and $25 \mathrm{~kg}$ were provided with a gastric fistula (GF) and in four instances with a vagally-denervated fundic Heidenhain pouch (HP). They were deprived of food but not water for 18 hours before each test and at least 48 hours elapsed between tests.

\section{EXPERIMENTS}

Each test began with a 30-minute basal period, after which HG-14-I or HG-17-I was given by intravenous infusion at rates of $50,100,200,400$, or $800 \mathrm{pmol} / \mathrm{kg}$ $h$. The lowest dose was infused first, with doubling of the dose every 30 minutes.

Gastric juice from the fistula and pouch was collected continuously and divided into 10-minute samples. Acid concentration was measured by titration of a $0.2 \mathrm{ml} \mathrm{sample} \mathrm{to} \mathrm{pH} 7.0$ with $0.2 \mathrm{M} \mathrm{NaOH}$. 
The secretory response to each dose of gastrin was expressed as the mean acid output ( $\mu \mathrm{mol} / 10 \mathrm{~min}$ ) during the final two 10-minute periods of each dose.

Venous blood samples were obtained from a leg vein of a limb other than that used for gastrin infusion. Two blood samples were taken during the basal period and two samples were taken during the final 10 minutes of infusion of each gastrin dose. On completing the final dose the infusion line was withdrawn rapidly and blood samples taken at two, four, six, eight, and 10 minutes to determine disappearance rates. Ammonium oxalate-potassium oxalate was used as an anticoagulant. After separation the plasma was stored at $-20^{\circ} \mathrm{C}$ to await radioimmunoassay.

Radioimmunoassay was performed as described previously (Stern and Walsh, 1973) using antibody 1296 (Walsh et al., 1974). Samples of gastrin solutions infused were retained as radioimmunoassay standards. Basal gastrin concentration was subtracted from all subsequent values in expressing results.

Plateau serum gastrin concentration for determination of half-time, clearance and volume of distribution was taken as the mean of the two values obtained during infusion of the final dose. Using gastrin levels at times two, four, six, eight, and 10 minutes after infusion in addition, the one compartment model, $\Delta$ gastrin $=\mathrm{Ae},-\mathrm{kt}$ was fitted separately for each dog with the non-linear least squares programme BMDP3R (Dixon, 1975). The half-time was calculated from the relation: $t_{\frac{1}{1}}=$ $0 \cdot 693 / \mathrm{k}$. The clearance rate of gastrin was calculated from the equation: $C=D / G$, where $C$ is the clearance in $\mathrm{m} 1 / \mathrm{kg}$-min, $\mathrm{D}$ is the dose of gastrin in $\mathrm{pmol} / \mathrm{kg}$-min, and $\mathrm{G}$ is the plateau serum gastrin in $\mathrm{pmol} / \mathrm{ml}$. The volumes of distribution were calculated from the plateau principle (Goldstein et al., 1968) using the equation: $V=D / G k$, where $V$ is the volume of distribution as a fraction of body weight $(\mathrm{ml} / \mathrm{kg})$ and the other variables and constant have the meanings described above.

\section{Results}

aCid Stimulation (Figs. $1 \mathrm{a}$ and $1 \mathrm{~b}$ )

The responses to 100,200 , and $400 \mathrm{pmol} / \mathrm{kg}$-h were chosen for analysis in that they represent approximately linear portions of the dose-response curves. Because of the tendency for variation among animals to increase with increasing dose, square root of acid output was chosen as the response measure. Analysis of the total response to the doses selected showed no statistically significant differences between the two molecular forms of gastrin in either GF response (paired $t=1 \cdot 46$ ) or HP response (paired $t=$ 1.28). Comparison of potency by $3+3$ dose parallel

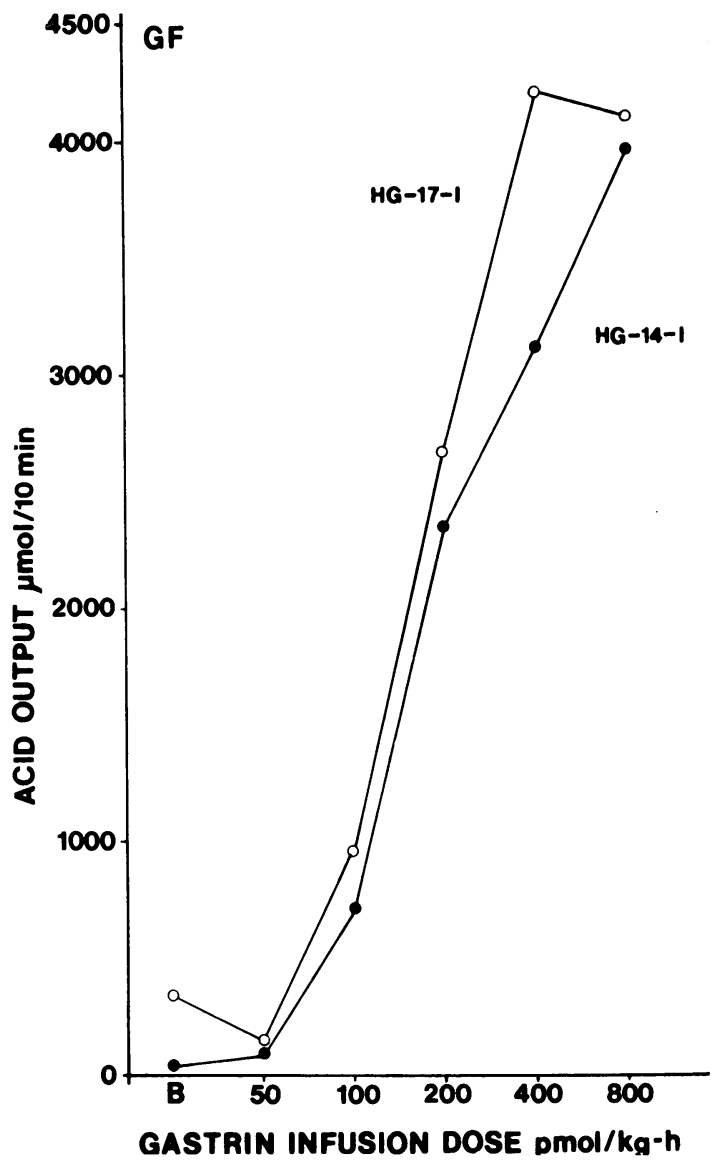

Fig. 1a. Dose-response curves obtained with equimolar doses of HG-14-I and HG-17-I in five dogs with gastric fistula.

line assay (Colquhoun, 1971) revealed that HG-14-I was 0.7 times as potent as HG-17-I based on GF responses, and 0.6 times as potent based on HP responses.

\section{INCREMENT IN SERUM GASTRIN DURING} INFUSION

Similar molar increases in immunoreactive gastrin over basal values were produced by equimolar infusions of the two gastrins (Fig. 2). The increment in serum gastrin was linearly related to infusion dose, indicating that disposal rate and space of distribution did not vary with dose over the range studied. The similarity between the slopes for the two gastrins $(0.48$ for $G-17$ and 0.51 for $G-14)$ indicates that they have similar rates of disposal. The mean plateau gastrin increment during infusion of 800 


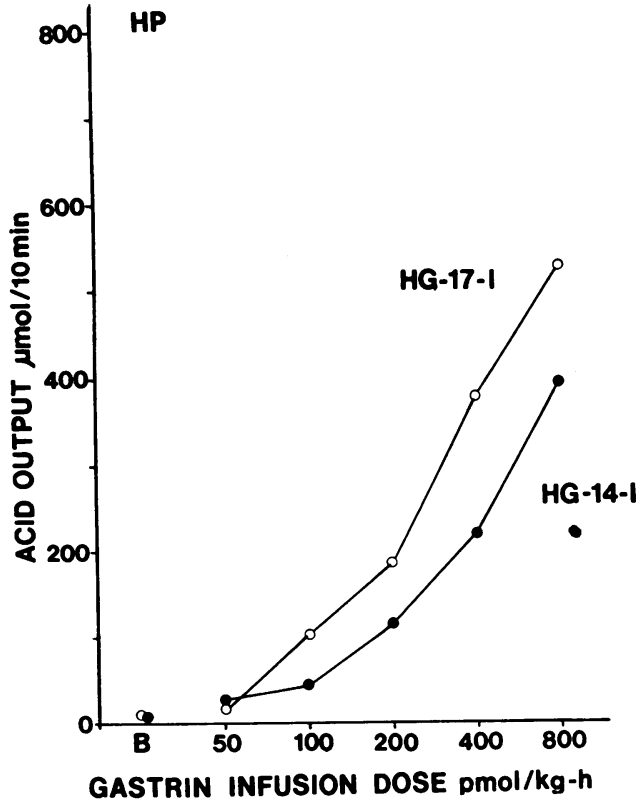

Fig. 1b. Dose-response curves obtained with equimolar doses of HG-14-I and HG-17-I in four dogs with Heidenhain pouches.

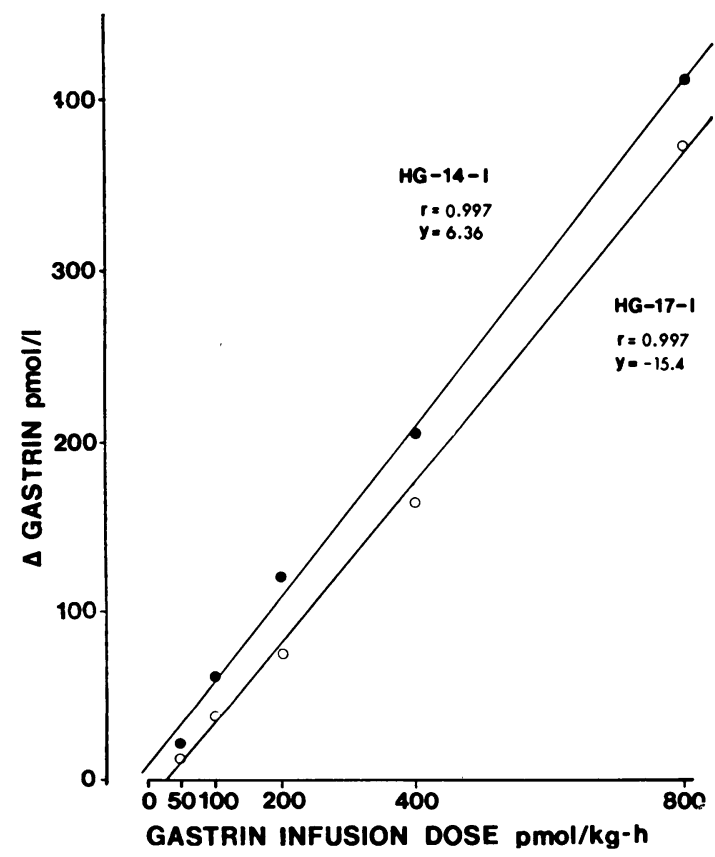

Fig. 2 Increments in serum immunoreactive gastrin in response to various infusion rates of $H G-14-I$ and HG-17-I in five dogs. pmol/kg-h of HG-17-I and HG-14-I was $372 \cdot 8 \pm$ SE $47 \mathrm{pmol} / 1$ and $411 \pm \mathrm{SE} 60 \mathrm{pmol} / \mathrm{l}$ respectively, a statistically insignificant difference (paired $t=1 \cdot 2$ ).

\section{CLEARANCE RATES AND VOLUME OF} DISTRIBUTION

The mean clearance rate for $\mathrm{HG}-17-\mathrm{I}$ was $37 \cdot 8 \pm$ SE $4.2 \mathrm{ml} / \mathrm{kg}$-min, compared with $35.4 \pm \mathrm{SE} 5 \cdot 3$ for HG-14-I $(t \pm 1 \cdot 0, \mathrm{P}>0.05)$. The calculated volume of distribution was $92 \pm \mathrm{SE} 22 \mathrm{ml} / \mathrm{kg}$ for $\mathrm{HG}-17-\mathrm{I}$, and $142 \pm$ SE $19 \mathrm{ml} / \mathrm{kg}$ for HG-14-I $(t=1 \cdot 9, \mathrm{P}>0.05)$.

\section{SERUM GASTRIN HALF-TIME}

Both forms of gastrin were removed rapidly from the circulation, and serum concentrations had returned almost to basal levels within 10 minutes of stopping infusion. The calculated mean half-time for HG-17-I was $1.7 \pm \mathrm{SE} 0.4 \mathrm{~min}$ and for HG-14-I it was $2 \cdot 8 \pm$ SE $0.2 \min (t=1.9, \mathrm{P}>0.05)$.

\section{Discussion}

There are now six chemically defined molecular forms of gastrin with known biological activity, and three immunoreactive forms which have uncertain structure and no known biological activity. Sulphated and unsulphated G-14 belong to the former category. In addition to their presence in gastrinoma tissue (Gregory and Tracy, 1974) they comprise a small fraction of immunoreactive gastrin in the serum of patients with the Zollinger-Ellison syndrome and are probably present in the serum of normal subjects (Rehfeld and Stadil, 1973).

Equimolar infusion rates of HG-17-I and HG-14-I produced the same molar increments in serum gastrin concentration. The acid secretory response to HG-14-I was less than to HG-17-I but the difference was not significant when judged by conservative statistical tests. It is conceivable that this difference in potency will become significant when larger samples are tested. The thesis that HG-14-I may be truly less potent receives some support from recalculation of data presented by Debas, Walsh and Grossman (1974). Using correct extention coefficients the revised potency ratios become $\mathbf{0 . 7 5}$ for HG-14-I relative to HG-17-I in terms of GF response, and 0.57 in terms of HP response, figures in close accord with those of the present study.

Supported by a Veterans Administration Senior Medical Investigatorship (M.I.G.) and by NIAMDD grants 8354 and 17328 to CURE (Center for Ulcer Research and Education). David Carter was supported by the Wellcome Trust. Computing assistance was obtained from the Health Sciences Computing Facility, UCL.A, supported by NIH Special Research Resources grant RR-3. 


\section{References}

Colquhoun, D. (1971). Lectures on Biostatistics. An Introduction to Statistics with Applications in Biology and Medicine. Clarendon Press: Oxford.

Debas, H. T., Walsh, J. H., and Grossman, M. I. (1974). Pure human minigastrin: secretory potency and disappearance rate. Gut, 15, 686-689.

Dixon, W. J. (editor) (1975). BMDP: Biomedical Computer Programs, pp. 541-572. University of California Press: Los Angeles.

Goldstein, A., Aronow, L., and Kalman, S. M. (1968). Principles of Drug Action, p. 292. Harper and Row (Hoeber): New York.

Gregory, R. A., Tracy, H. J., Harris, J. I., and Runswick, M. J. (1979). Minigastrin: corrected structure and syn- thesis. Hoppe-Seylers Zeitschrift für Physiologische Chemie, 360, 73-80.

Gregory, R. A., and Tracy, H. J. (1974). Isolation of two minigastrins from Zollinger-Ellison tumour tissue. Gut, 15, 683-685.

Rehfeld, J. F., and Stadil, F. (1973). Gel-filtration studies on immunoreactive gastrin in serum from Zollinger-Ellison patients. Gut, 14, 369-373.

Stern, D. H., and Walsh, J. H. (1973). Gastrin release in postoperative duodenal ulcer patients: evidence for release of duodenal gastrin. Gastroenterology, 64, 363-369.

Walsh, J. H., Trout, H. H. III, Debas, H. T., and Grossman, M. I. (1974). Immunochemical and biological properties of gastrins obtained from different species and of different molecular species of gastrin. In Endocrinology of the Gut, pp 277-289. Edited by W. Y. Chey and F. P. Brooks. Slack: Thorofare, N.J. 